Article

\title{
Keep the Fire Burning: Exploring the Hierarchies of Music Fandom and the Motivations of Superfans
}

\author{
Jessica Edlom ${ }^{1, *}$ and Jenny Karlsson ${ }^{2}$ \\ ${ }^{1}$ Department of Geography, Media and Communication, Karlstad University, Sweden; E-Mail: jessica.edlom@kau.se \\ ${ }^{2}$ CTF-Service Research Center, Karlstad Business School, Karlstad University, Sweden; E-Mail: jenny.karlsson@kau.se \\ * Corresponding author
}

Submitted: 15 January 2021 | Accepted: 15 March 2021 | Published: 5 August 2021

\begin{abstract}
The Internet has changed how music fans come together and how the music industry connects to and communicates with fans. To understand the incentives for becoming a fan and why fans take part in an artist brand, this article considers the diversity in a particular fan community, including its hierarchy and roles. Fans have different levels of engagement, knowledge, and status, both inside and outside a fan community. To extend the existing research on fan hierarchies into the digital promotional culture, this study focuses on the case of the Swedish music artist Robyn and her Facebook fan community Konichiwa Bitches. To gain insights into a complex online research arena, we use a qualitative and digital ethnographic approach in both online and offline contexts. The article provides an understanding and conceptualization of fan hierarchies, focusing on the top of the hierarchy, superfans and executive fans, and on their incentives for engagement. These high-level fans function as a key connecting point between the brand management and the fans, thus taking fandom a step further and enhancing the brand.
\end{abstract}

\section{Keywords}

fandom; fan community; fan hierarchy; engagement; music industry; superfan; value co-creation

\section{Issue}

This article is part of the issue "Complexity, Hybridity, Liminality: Challenges of Researching Contemporary Promotional Cultures," edited by lan Somerville (University of Leicester, UK) and Lee Edwards (London School of Economics and Political Science, UK).

(C) 2021 by the authors; licensee Cogitatio (Lisbon, Portugal). This article is licensed under a Creative Commons Attribution 4.0 International License (CC BY).

\section{Introduction}

Music fans are not all the same; they have different levels of engagement, knowledge, and status, both inside and outside a fan community, as well as online and offline. Digitalization, marketization, and globalization have altered the conditions of the music industry, one that has adapted to the online environment and realized the benefits that social media can provide (Baym, 2012; Choi \& Burnes, 2013; Wikström, 2009). Because of the high level of consumer interaction (Gamble \& Gilmore, 2013), music actors have become deeply dependent on engaging with audiences and fans. Active, cocreative audiences are sought after and used to fos- ter communication in transmedia marketing campaigns (Zeiser, 2015), which encourage fan engagement both online and offline. The goal is to induce fans to act in accordance with the marketing strategy and work within the campaign both as individuals and as a group. However, in the highly commercialized and strategized music market, there is a lack of knowledge on the music fan's perspective of being part of a fan community (Baym, 2012), and previous research has called for a better comprehension of fans in the digital era (Schrøder, 2019; Schroeder, 2014; Ytre-Arne \& Das, 2019). A deeper understanding is therefore needed of fan communities' close cooperation with music artists/brands and of fans' experiences of engagement and what this gives them, 
as well as of the fans' various roles (as suggested by, for example, Galuszka, 2015) in promotional cultures. In the music industry, the term superfan is increasingly used to describe highly engaged fans, who are seen as the most important to reach and use as drivers in marketing campaigns. This label is also used among fans. We argue that this term has not been rigorously analyzed or conceptualized in previous research. The aim of the article is twofold: to explore and conceptualize fan hierarchies within fan communities, and to create an understanding of superfans that encompasses their engagement and their relations with other fans and the music artist.

The following research questions are posed:

\section{RQ1: What is a superfan?}

RQ2: How are fan hierarchies formed within a fan group?

RQ3: What do the most engaged fans contribute to the fan community (and to the brand) both online and offline?

The article draws on digital ethnography (Hine, 2015; O'Reilly, 2012) following the fan group of music artist Robyn, both online and offline, with a special focus on her Facebook fan community Konichiwa Bitches (KB). The rationale behind this design is to discover the meaning of a cultural phenomenon (Markham, 2017) and to gain multidisciplinary and in-depth insights into fans' social lives as they unfold, in other words, how fans act, feel, and engage in relation to the actual context and community (O'Reilly, 2012). In so doing, we provide an understanding and conceptualization of a fan hierarchy, focusing on the top of the hierarchy, the superfans, and also identifying the top superfans-the so-called executive fans-and the fans' incentives for engagement. This article proceeds as follows: In the next section, we review the literature on fan hierarchy and fan engagement that we draw on in our analysis. We continue by presenting the methodology used and how the study was conducted, followed by a description of the findings. The article ends by discussing the results and contributions of our study in relation to the previous research.

\section{Theory}

\subsection{Fan Hierarchy}

Duffett $(2013$, p. 2) defines a fan as someone having a "positive, personal, relatively deep emotional connection" with an artist or a brand. In the later part of the 20th century, the interest in fandom increased to encompass fans having engaging relationships with popular culture and mediated artefacts (Holt, 2004), with other fans (in fan communities; Jenkins, 1992), and as consumers with a unifying interest (brand communities; Cova et al.,
2011; Sandvoss, 2005). Hao (2020, p. 25) focuses on so-called consumer fandom and argues for further conceptualizations of fandom in order to understand "the role of individual characteristics and social related variables as the drivers of consumer fandom" within promotional industries.

Social interaction is central in fandom, and fan communities offer fans a sense of belonging (Jenkins, 1992, 2006), provide structures for collectiveness, and become a "close-knit network of people who look after each other on the basis of shared interest and values" (Duffett, 2013 , p. 246). Gathering, sharing, and spreading information about the object of interest is central to forming affective links among the members of fan communities (Hoxter, 2000). The collection of knowledge is also a way to gain power over less educated fans and elevate one's status in the group (Kermode, 1997). There is a social hierarchy based on the fans' level of knowledge of and access to the object of fandom (Hills, 2002). MacDonald (1998) defines five distinct types of hierarchy based on knowledge, access, leadership, venue, and fandom level or quality, and argues that fans who are at the top of all five hierarchies are executive fans. Tulloch and Jenkins (1995, p. 149) refer to executive fans as those who are "executives of the fan clubs and magazines." Jenkins (1992) notes that fan knowledge serves to distinguish people within the fan community. The expertsthose who have accumulated the most knowledge-gain prestige within the group and act as opinion leaders. These senior or expert fans within the group thus acquire a kind of discursive power. According to Tulloch and Jenkins (1995), they establish, form, and control how the other fans in the group read and interpret fan objects. In this way, executive fans are "able to control topics of discussion and maintain their own high level of discursive power" (Williams, 2004, p. 4).

Pierre Bourdieu's (1984/2010) work on the processes of cultural distinction contributes to the analysis of how fan "status" is built up. The "capital" of being a fan consists of tacitly recognizing the "rules" of a fan culture and of attempting to build up various types of skills, knowledge, and distinction within that context, also called "fan cultural capital" (by Fiske, 1992). Hills (2002, p. 57) expands on this by suggesting that "fan social capital" must be taken into consideration when researching fans, defining it as "the network of fan friends and acquaintances that a fan possesses, as well as their access to media producers and professional personnel linked with the object of fandom." Fan social capital cannot be entirely divorced from fan cultural capital, as it is likely that fans with very high fan cultural capital will become executive fans and will therefore possess a high level of fan social capital (Hills, 2002) and identify with others who are like them.

Milne and McDonald (1999) argue that fan identification can be divided into three levels: low (social fans), medium (focused fans), and high (vested fans). Fans characterized as high are the most loyal and engaged, 
spending considerable time and money on their favorite artist in long-time relationships. They see themselves as a part of an artist's extended family, which they have a vested interest in protecting and supporting. These highlevel fans are increasingly referred to as superfans. This term refers to Duffett's (2013) definition of a fan, but the superfan has a much deeper connection with the brand than a lower hierarchy fan. Adams (2013), who studied the role of superfans in sports (and their trademark infringement of the sports brands they are connected to) refers to them as "die-hard fans" who cheer on their team "from the first play until the game clock expires" (2013, p. 631). Van den Bulck et al. (2016) studied loyalty and fan emotion intensity among superfans in a television context. Liang and Shen (2016) studied how feedback from superfans can propel the revenue of creative industries - referring to superfans as highly vested fans. However, although the term superfans is increasingly used in the media and music industry, it has not yet been thoroughly described and conceptualized in the previous research.

In a talk at a music industry conference in Midem, France, Hyatt (Midem, 2013) described a hierarchy of fandom comprised of superfans at the top, followed by engaged fans and ambient fans. The superfans are those within a community who are considered to be potentially the most lucrative, those who will "pay you the most" (Midem, 2013). The engaged fans are those who are somewhat aware of the brand. They may go to one show and buy a couple of downloads per year, but the brand is probably not in their top 10. They 'like' the brand on social media and follow it online but probably not very often. Ambient fans are any people in the brand's network; they may be a friend on Facebook or follow the brand on Twitter, but they are not consumed by it. Hyatt argues that, from the industry perspective, it is vital to know who the superfans are-those who share and comment on everything-because it is important to involve fans in promotions, such as contests, in order to move them from level 3 (ambient fans) to level 2 (engaged fans), and from level 2 to level 1 (superfans), so as to create dedicated followers and customers. It is therefore important to nurture the superfans among the overall customers by creating customer experiences that make them loyal, lifelong fans (see, for example, $\mathrm{Wu}$, 2012), who are also influential within their social networks. Thus, although constituting only a small percentage of a fan community, superfans are highly important in driving and controlling the community and also central to marketing the brand.

Relating to the different conceptualizations of fan hierarchies, we build on Hyatt's (Midem, 2013) and MacDonald's (1998) terminology in this study and argue that it reflects fandom within contemporary promotional cultures. However, the understanding of fandom in the previous research primarily takes an industry perspective, and insights from the fans' own perspectives are limited as to how fan hierarchies are formed within a fan group and how fans engage with and contribute to each other, to the community, and to the artist.

\subsection{Fan Engagement and Value Co-Creation}

The transformation of the music industry and the transition of communication channels toward digital media platforms allow music fans to access and enjoy music, even by-passing the music labels and sharing and creating content with each other at no or little cost (Wikström, 2009). Fans can also engage with other fans and with the music artists in new ways (Baym, 2018). Regarding fan and audience engagement, there are two sides: engagement as an audience experience; and engagement as an industry concept, in which the engagement is used as a means of value creation and marketing, and as a measure of success in these endeavors (Jenkins et al., 2013). Audience engagement on social media is often characterized by low to high activity (see Malthouse et al., 2013; Muntinga et al., 2011), and engagement behavior can be positively and negatively valenced and categorized according to level of intensity (Dolan et al., 2015). Generally, music fans are highly active and loyal in their engagement around the object of their affection (Chung et al., 2018; Fiske, 1992; Gray et al., 2017).

Through the use of social media, the brand/firm has the opportunity to follow and learn from the actions and interactions of customers (fans) and, in the process, gain information that can be valuable to their goals, but that can also be misused in certain instances, such as creating working consumers (see for example, Fast et al., 2016; Terranova, 2000). Diverse actors (advertisers, platform owners, music labels, etc.) profit on users' engagement, conducting what several scholars have identified as a type of unpaid work (see, for example, Morris, 2014). Baym $(2015,2018)$ calls this "relational labor," referring not only to audience engagement but also to the work conducted by musicians and artists toward building and maintaining relationships with their fans. Despite this risk of misusing users' engagement, social media also provides an opportunity for value co-creation, both for audiences and the industry.

Rather than being produced by an artist, for example, and delivered to and consumed by fans, value is co-created mutually between different actors (Vargo \& Lusch, 2004, 2016). Thus, members of brand communities contribute to co-creating a brand (Ind et al., 2013) and its content, playing an important and dynamic role in the value co-creation process (Pongsakornrungsilp \& Schroeder, 2011). Moreover, participation in online communities often leads to positive fan experiences that "bring value through enhancing an individual's sense of social identity" (Choi \& Burnes, 2013, p. 47). This desire of fans for interaction makes it important to understand not only the artist/fan relationship but also the fan/fan relationship. 


\section{Method}

\subsection{Research Design and Case Selection}

To get closer to the experience of the fan hierarchy phenomenon (Markham, 2017) and to gain an understanding of superfans within fan communities, we used a combined research methodology and selected the case of the fan universe of the Swedish music artist Robyn. The case was selected for three reasons: First, Robyn is a well-known Scandinavian artist with a large fan base; second, Robyn made a comeback in late 2018 and created a new Facebook fan community that quickly grew to include fans from all over the world; and third, this case provides a rich empirical context because the artist uses social media to communicate with her fans, who are also active in their relationships both with the artist and among themselves.

The main focus is on the Robyn fans' Facebook group KB, created by Robyn's management in August 2018 as part of the release campaign for her new album Honey and the marketing events connected to the release. At first, the group's content focused primarily on branded items and information about campaign eventsfor example, a gamified competition that gave fans the opportunity to win tickets to a secret gig and priority in relation to upcoming concerts. The game was directed at Swedish fans, but functioned as an enticement even for fans outside Sweden when introducing the Facebook group. When KB started, it filled a gap in Robyn's existing fan community by providing a digital forum for fans to engage with other fans and the artist. Since then, the group has grown and expanded to include fans from all over the world, and, by the end of 2020 , over 3,500 fans were members of the community. Although it started as a management-led branded community, KB is now partly administered by fans and is focused mainly on fan activity: fan conversations, sharing of information, videos, and 'Robyn news.' Activities also include arranging fan concerts and initiating get-togethers.

An ethnographic approach facilitates getting close to and deeply understand the object of study (Hine, 2015), and, in this study, it fostered an understanding of Robyn's fans and the fan hierarchies in the community. Marcus (1995) stresses the need to follow "the thing" to understand it, and a multi-sited ethnography is crucial in doing that. Investigating a digital, networked object of study should focus on mobility in relation to what is happening across platforms during the study period, resulting in a multi-sited digital ethnography (Hine, 2015; Pink, 2016). This method makes it possible to focus on the social spaces that emerge through the use of the Internet and also on those existing beyond it (Hine, 2015). In contemporary social life, people combine online and offline experiences, as the Internet is so built into our everyday lives that we hardly recognize it. Yet, it can also be challenging to research as it is complex, moving, and everchanging. Therefore, to gain a holistic understanding of the actual context and community (O'Reilly, 2012), we followed the fans' activities both online and offline.

\subsection{Data Collection and Analysis}

Empirical data were collected between May 2018 and December 2020. As digital ethnography involves engaging in the field, watching what happens, and listening to what is said (Hine, 2015; O'Reilly, 2012), we searched for Robyn-related content in social channels and digital news media. We also followed and participated in blogs on social media platforms to gather relevant online media material (see, for example, Pink, 2016; Postill \& Pink, 2012). In addition, since the researcher should "immerse herself in the setting, and... try to see life from the point of view of those who habitually populate that setting" (Hine, 2015, p. 19), we actively listened, watched, discussed, participated, and shared information in forums, digital sets, and offline. On a daily basis, we scanned $\mathrm{KB}$ and studied its posts, pictures, texts, activities, and conversations, taking several hundred screenshots in the process. All data were analyzed in a qualitative content analysis that identified similarities and relevant topics and themes, which were then described and interpreted.

In addition, we negotiated access with the key gatekeepers and made ourselves socially acceptable, as Hine (2015) suggested. To gain insight into the members' feelings and experiences of being fans and members of the group, we conducted a survey on KB in 2018. It was designed with 10 questions, both multiple-choice and open-ended; the latter were intended to encourage the fans to elaborate on their thoughts, feelings, and experiences so that we could reflect on what is valuable to them. 18 responses to the survey and many posted comments were collected. A total of 11 interviews were conducted with fans at diverse engagement levels, from regular listeners to active superfans. The fans on KB were invited to take part in the study, as well as the fans we met in the offline setting of the Robyn concert in Stockholm in August 2019. Attending the live concert also allowed us to gain an understanding of how fans interact with one another and with the artist. The selection of fans was based on our decision to approach individuals who were purchasing Robyn merchandise, as we believed that fans were more likely to buy merchandise than non-fans/regular listeners. Some were also approached after other fans suggested them as superfans. The semi-structured interviews lasted between 14 and 60 minutes and were audio-recorded and transcribed. The interviews were conducted with both men and women (seven men and four women), aged 17 to 49, from three countries, Canada, the United States, and Sweden.

Ethnography as a method and process is explorative and adaptive, and the researcher should be open and agile in both the research strategy and the process and adopt a reflexive approach throughout (Hine, 2015). Iteration between the data collection and analysis 
characterized our research process. Inspired by the constant comparative method (Strauss \& Corbin, 1990), we began analyzing the data by identifying open codes. This was followed by axial coding, which uncovered the key themes for each research question. These are described in the findings section and elaborated upon in the discussion section. We continued by using selective coding to integrate our themes with the theories on fandom, fan engagement, and fan hierarchies to create an understanding of superfans and their motivations, actions, and value co-creation.

\subsection{Validation of Results (Trustworthiness)}

According to Lincoln and Guba (1985), trustworthiness is the most important criterion for assessing the quality of qualitative research. As recommended by Wallendorf and Belk (1989), the findings of this study have been validated by triangulation across the methods, researchers, respondents, and sources. This article is based on data from a single case study, but, as the online community is rich and vibrant, these data provide fruitful insights into our understanding of the superfans and hierarchies of the music fandom phenomenon. The case study took place in the context of the music industry; however, as the focus of the study is fans and superfans, we believe that its results may be applicable and transferable to other contexts having a focal actor and fans. The aim is not to generate a statistical generalization but rather to reap fruitful insights into the studied phenomena and to contribute to the development of the concept as an analytical generalization (Yin, 2013).

The massive amount of online data has implications and challenges for research as it can affect the choice of appropriate data and how it is gathered (Boyd, 2015). Knowing where to find information and possessing the related knowledge of how to understand it contributed to our selection of data appropriate to the study and to our gaining access to the data. Furthermore, the data were analyzed and categorized independently by the researchers and then compared and cross-checked to make sure that the findings represented the various types of respondents/fans.

A main concern, beyond being open and transparent about our intentions, related to the fans' privacy and preserving their anonymity. It is useful to show content from social media in presenting the results, but the ethics of digital ethnography, as outlined by the AolR Ethics Working Committee (Franzke et al., 2020; Markham \& Buchanan, 2012), proscribe the showing of content that can be traced online. In this case, we studied a closed Facebook group, which made the content untraceable. Furthermore, the quotes are presented with pseudonyms. The respondents' anonymity contributed to their giving honest answers. In addition, as the respondents' remarks were probed during the interviews, misunderstandings could be minimized because they were able to elaborate on their answers and expla- nations as well as their posts, which also positively influenced the study's credibility. These various factors contributed to the data's confirmability.

\section{Findings}

This section discusses the perceived hierarchies of fandom, with a focus on superfans and executive fans. It also reports on how fans build hierarchies and on what, how, and why superfans contribute to the fan community.

\subsection{Blow My Mind: Incentives for Deep Engagement}

The incentives of Robyn's fans include enjoying the relationship with other fans and engaging with each other both online and offline. Fans in the community build a common fandom together over time and create memories together: "I feel like a part of something. I feel less alone and less weird when I know that others are obsessed as well" (Robin, 2019). Another superfan stated, "It is important to share anything you feel passionate about, and I am passionate about Robyn's music" (Bella, 2019). KB provides the opportunity for fans to meet like-minded people, especially when they lack peers in physical proximity.

Fans are active in sharing, commenting, starting conversations, and arranging events. These activities are intended to provide value for themselves, the community, and the artist, with the aim of cultivating fandom within the community: "I want to try and do something to make everyone interact. Like bonding over stuff... or like, what's your favorite memory with stuff from Robyn?" (Bill, 2019). Arranged meetups online and offline also provide a space for fans to co-create value with each other; for example, in relation to upcoming concerts, fans invite others to share apartments and travel together to venues. Another example relates to a game conducted, both online and offline, for fans to win tickets to a secret gig. As Elisabeth (2019) described, "Three weeks of fun, swap meets, making new friends! We still keep in contact!" In general, Robyn fans show an openness and a deep interest in Robyn and her artistry but also an interest in each other.

The majority of the respondents described a fandom that has been going on for many years and involves following the artist in numerous ways, such as collecting things, following news, going to concerts, mimicking styles, and so forth. For example, Maria (2019) cuts her hair in the same style as Robyn and collects "all that I can get a hold of." Pictures of her collection are shared on KB for others to enjoy; they are requested by other fans and are a focus for interaction and value co-creation as they provide specific insights into Robyn's history, which is valuable for superfans in allowing them to come closer and 'get to know her.' Coming near to Robyn (both physically and emotionally) is central to her fandom and to dedicated superfans. James (2019) states, "She did touch my head when she crowd-surfed at one 
point, but yeah....Patted me on the head... I'm that sort of fan... it became like a... religion and I was like, oh my God-this is amazing!" For others, Robyn is a long-time inspiration in other ways; as Bill (2019) explains, "You could say that if there was no Robyn there would be no me....Influenced by Robyn, I also started my own record label and gave out my own music. She is an inspiration." Fandom thus functions not only as a way to draw closer to and find similarities with the artist but also as encouragement for fans to be creative and go their own way.

\subsection{Stars 4-Ever: Conceptualizing the Hierarchy of Fandom}

There is generally high activity by fans in the Robyn social channels. However, community data shows that some fans are clearly more active and influential than others, which indicates that there are different types of fans. The least engaged are the ambient fans, such as Lars (2019), who went to a Robyn concert and liked her music but did not label himself as a fan, even though he bought a Robyn t-shirt at the venue. Ambient fans listen to and like the music, but they typically do not become dedicated. The ambient fans of the KB group are not very active; they follow the discussions and news without participating much in interactions.

On another level, many of the group members in $\mathrm{KB}$ act as engaged fans who express their affection for the artist in various ways. Studying Robyn's official social channels shows that many fans are highly active in liking, commenting, sharing, and so on. Their engagement can also involve being active in real life, for example by going to concerts, listening to music, meeting other fans, and collecting things. Carl (2019) claimed not to be a "huge fan, but I have probably been one anyways because I have listened a lot to her." Many are faithful and come back again and again, which also suggests that they are engaged with their object of fandom.

Other members of KB see themselves as superfans and are part of a community of deeply invested fans. As Elisabeth (2019) stated, "We are an 'elite' group of Robyn diehard fans," and James (2019) added, "It is where the hardcore superfans are," fans who share a great deal of news with each other and find, for example, old videos, interviews, and fan artefacts of various kinds and share experiences related to Robyn. Some people more or less live Robyn and her values and explain that she is highly important to them. According to several of the respondents, a superfan is somebody who is highly invested in the fan object and can be so in various ways: by being very engaged, and (relating to quality/level in Hills's [2002] typology) by possessing deep knowledge and a high fan social and cultural capital. The community data also shows that superfans are the drivers of new offerings in the fan community, for example by initiating activities, such as challenges between fans and meetups with fans, and by starting discussions in which fans are invited to share their personal experiences of fandom and other aspects of their private life with their fandom friends. The superfan can thus be seen as an important driving force in the fan community in the sense of contributing to interaction and building the community culture. These fans are often seen as leaders, influencers, and experts by others in the group.

Superfans also arrange special Robyn events on their own, investing their own time to make them happen. For example, since 2011, three superfans have organized the Robyn celebratory party, 'This Party Is Killing You,' to bring fans together, which, in the beginning, was free (although today a small fee makes it possible to continue). As Nancy (2019) explains, "None of us are fulltime DJs. We all have other jobs, so this is something we do because we love it... as people started showing up, we were like, oh yeah, we are here to party. This is great!....We felt energized. The excitement with the people that came." Brian (2019), one of the founders explained, "We did it for fun. People kept coming, we had a good time, we kept doing more of it. We became really invested in her career, her fans, and everything she was doing." These events play an important role for fans by demonstrating that they are part of something bigger, and this sense of group inclusiveness often evolves into friendships between superfans in real life. The Robyn management discovered the parties, via the superfans' high engagement with the artist, and started supporting them with, for example, merchandise and attention. This management intervention led to Robyn eventually attending one party, causing great joy among her fans: "Suddenly we see her walk into the venue. It was so cool; you could hear the roar....It was really above and beyond our expectations" (Brian, 2019). Her attendance created yet another enticement for the community. As these celebratory parties build both the Robyn community and brand, this implies that superfans can act as amplifiers of the brand, inviting other fans to take part in the experience. Although these parties are created by superfans, and they were even before the management learned about them, the brand definitely benefits from such events. The management could potentially use them as a sophisticated marketing avenue, although our results show no such interference or involvement.

Related to the descriptions of the levels and hierarchy of fans (Hills, 2002; MacDonald, 1998; Midem, 2013; Milne \& McDonald, 1999), the empirical data suggest various levels of superfans: Some are deep in their knowledge and the quality of their fandom, and others are highly active in spreading news, stirring conversations, and being central in the fan group. There is also a clear distinction between being a superfan and an executive fan, the latter being on top of all dimensions of fandom. The most active superfans in the group have a clearly elevated status within it. They are often seen as leaders and as possessing greater fan social and cultural capital. Others in the group could readily point out who these people were: “Yeah, there are definitely a few, and I can't name them right now, but obviously $X$ is very active on 
there" (James, 2019). As reflected in the community data, the executive fans steer a large amount of content in the $\mathrm{KB}$ group and are sometimes invited by the management to become administrators. When this happens, it indicates that the executive fans have climbed to the highest level in the fan hierarchy. Despite their new status in the group, however, they are free to act without the management steering their engagement although, from time to time, the management encourages the executive fans to arrange activities connected to the artist.

\subsection{Monument: Formation of Hierarchies Within the Fan Group}

Advancing in the fan hierarchy happens over time, either intentionally or not. Some fans seem to actively strive to gain a higher position and status within the group. This can be obtained by recognizing the rules of fan culture and building up skills, knowledge, and distinction, which can lead to the associated greater fan cultural capital and fan social capital. Having a social network of other fans as well as professional actors is important when one is high in the hierarchy, but fan cultural capital is seen as more important to becoming a top-level superfan or executive fan. The incentives can also be about self-branding; that is, they promote themselves within the community as the most engaged, as leaders or spokespersons in the group. Other members of the group also acknowledge this and recognize those whom they see as important influencers in the group.

Several respondents expressed that they became more active over time, for example by spreading content and working on events. Many in the group have been Robyn fans for a long time, even before the advent of social media, but the KB group gives them the opportunity to build relationships with other fans and express their increasing fandom over time, thus potentially leading to higher fan social and cultural capital and advancement in the hierarchy. However, none of the respondents expressed that they intentionally climbed the fan hierarchy. In fact, the friendly and like-minded atmosphere in the group makes the potential competition between members less of a motivation for doing this. Several members expressed that the group is "warm and giving" (Eric, 2019). Therefore, spreading content, etc. is not done to draw attention to oneself or improve one's status, but rather to share and co-create value. Nancy (2019) explains:

It is like sharing it with a group of friends....It's just like, oh, everyone in the community would like to see that, I have to share it immediately. It's really an authentic affection, and probably it does, of course, promote her brand, but you know it's less about that and more about our genuine love for her music.

The group shows a closeness in sharing what they believe is important for others to know, but some take it a step further. For example, the superfans that have been the most active over a long period of time have developed friendships, some even buying Robyn merchandise to give to each other as birthday gifts.

We observed a few potential tensions in the group hierarchy and in the creation of it. However, when a negative comment occurs, the members remind each other of the importance of maintaining a positive attitude and culture. Some fans do advance to having strong fan cultural and social capital and are seen as the most knowledgeable, as leaders and even executives, but there is the possibility that others will not succeed in this potential aspiration. Nevertheless, the empirical data suggest that it is closeness with the artist and with the community that is the central value for engagement, not the striving to advance in the fan hierarchy.

\section{Results and Discussion}

The article contributes by enlarging the understanding of the most engaged fans within the fan community, what constitutes a superfan and an executive fan, and how to become one. Even though the present study focuses on the top of the fan hierarchy, it also contributes by conceptualizing various levels of fans (see Figure 1): Ambient fans listen to and like the music but are not very active, following discussions and news without engaging; engaged fans are active and participatory within the fan group; and superfans are highly engaged and seen as experts who are central to the fan group. They are also influential and drive new offerings in the fan community that contribute to interactions and to building the community culture. Executive fans, the toplevel superfans, are the opinion leaders and, at times, the administrators, who have discursive power in the group.

Climbing the steps of the fan hierarchy can take time, and some fans actively strive to gain position and status. In the context of the hierarchy of fandom (MacDonald, 1998), the most engaged, knowledgeable, and influential fans are the executive fans (Tulloch \& Jenkins, 1995), those highest in the fan hierarchy in terms of knowledge, quality/level, and high fan social and cultural capital, as well as having access to the artist's sphere, stirring conversations, and being leaders. However, MacDonald (1998) and Tulloch and Jenkins (1995) do not agree on the relationship between superfans and executive fans and how they differ from each other. We argue that a superfan is at the top of the knowledge, quality of fandom, and fan social and cultural capital scales. The superfan is also seen as an expert and therefore often enjoys high status within the group. However, to reach the next level of superfandom, as an executive fan, the fan must also be on top of the scale regarding access to the object of fandom or the object's management, must be a facilitator of access to other fans, and must be regarded as a leader in the fan community. The findings show that the most active and engaged fans can become executive fans who may be designated by the artist's 


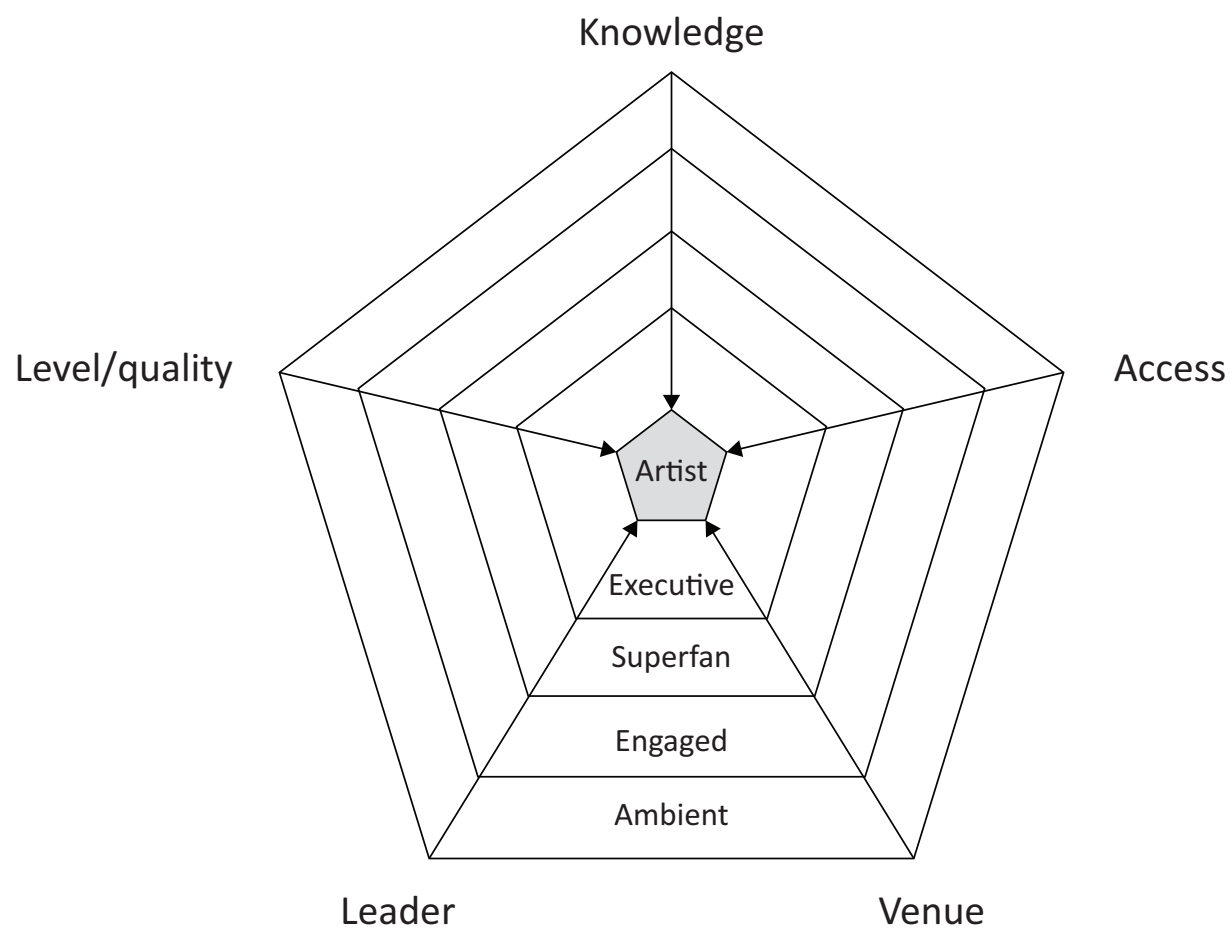

Figure 1. Hierarchies of fandom. Source: Adapted from Hyatt (Midem, 2013) and MacDonald (1998).

management as administrators of the fan page/brand community. As well as being high in knowledge and quality and possessing considerable social and cultural capital, executive fans initiate activities, create events, and have access to venues.

By rising in the hierarchy, the fans gain status, develop relationships with other fans, gain deeper knowledge, reach a higher fan quality level, and are seen as leaders in the community. They also come closer to and gain access to the artist/brand, with the possibility of influencing and extending the brand. These are the incentives for deep fan engagement as well as the drivers for changes in the hierarchy.

For the brands, deep fan engagement bridges the larger fan community and the brand. Superfans and executive fans are often used as mediators to initiate activities, gain access to the fan community, and build the brand. The risk of fans being misused via their engagement, such as in the case of working consumers, has been raised in previous research (e.g., Baym, 2015; Fast et al., 2016). However, the results of our study do not show the fans feeling used or exploited. At the same time, to our knowledge, the fans' engagement is unpaid, regardless of where they are in the hierarchy, including the executive fans who lead and administer the group.

Previous research suggests the need to advance the understanding of value co-creation (cf. Choi \& Burnes, 2013) and audience and fan engagement (cf. Galuszka, 2015; Ytre-Arne \& Das, 2019) by conducting fan-centric research with a focus on interactive experiences, integration, and co-creation between actors, as well as engagement practices that explore fans'/audiences' roles and efforts. The existing research mainly has an industry focus, whereas this study sets out to understand superfans and their motivations. This article explores the iterative and interactive nature of engagement and value co-creation in digital promotional cultures, by focusing on how fans engage both on social media platforms and in real life.

The article also provides an understanding of the distinctions between superfans and executive fans. The latter take fandom a step further by assuming leadership roles in the fan community and by creating relations with the artist brand's management, through which both the executive fans and the brand profit. The executive fan makes a personal business of the brand and can extend it into new venues, for example by organizing events and parties with merchandise related to the music artist. Such an expansion of the existing system of actors implies new ways of integrating resources and co-creating value, in which superfans and executive fans act as facilitators of value co-creation for the brand, whose management may or may not opt to monetize the relations and the engagement. The superfans and executive fans are the drivers and catalysts within the fan community, facilitating fan-to-fan interactions, relations, and engagement. However, previous research has identified a potential risk with fans that are too autonomous and engaged, at the expense of the brand (cf. Adams, 2013, regarding infringement), even though the findings of the present study indicate a balanced relationship.

The results of this article raise new questions about the motivations of those who are high in the hierarchy compared to those who are relatively low on the scale, 
and the possible tensions between them, a topic that is not discussed in our study but could be explored in future research. Further studies could also focus on the time aspect in fandom (i.e., the time spent as a fan), to discover if the time spent relates to one's status in the group and potential advancement in the hierarchy. We also recommend that the results of this study can be explored beyond the music scenario into other organizational and brand contexts.

\section{Acknowledgments}

The study has been conducted as a part of the research project "Music Ecosystems Inner Scandinavia," funded by the Interreg Sweden-Norway programme, EU, and Karlstad University, Inland Norway University of Applied Sciences, Innlandet Fylkeskommune County Council, Arvika municipality and Region Värmland.

\section{Conflict of Interests}

The authors declare no conflict of interests.

\section{References}

Adams, J. M. (2013). Flag on the play: Professional sports teams calling trademark infringement on their superfans. Jeffrey S. Moorad Sports Law Journal, 20(2), 631-662.

Baym, N. (2012). Fans or friends? Seeing social media audiences as musicians do. Participations, 9(2), 286-316.

Baym, N. K. (2015). Connect with your audience! The relational labor of connection. The Communication Review, 18(1), 14-22.

Baym, N. K. (2018). Playing to the crowd: Musicians, audiences, and the intimate work of connection. New York University Press.

Bourdieu, P. (2010). Distinction. Routledge. (Original work published 1984)

Boyd, D. (2015). Making sense of teen life: Strategies for capturing ethnographic data in a networked era. In E. Hargittai \& C. Sandvig (Eds.), Digital research confidential: The secrets of studying behaviour online (pp. 79-102). MIT Press.

Choi, H., \& Burnes, B. (2013). The Internet and value co-creation: The case of the popular music industry. Prometheus, 31(1), 35-53.

Chung, E., Farrelly, F., Beverland, M. B., \& Karpen, I. O. (2018). Loyalty or liability: Resolving the consumer fanaticism paradox. Marketing Theory, 18(1), 3-30.

Cova, B., Dalli, D., \& Zwick, D. (2011). Critical perspectives on consumers' role as 'producers': Broadening the debate on value co-creation in marketing processes. Marketing Theory, 11(3), 231-241.

Dolan, R., Conduit, J., Fahy, J., \& Goodman, S. (2015). Social media engagement behaviour: A uses and gratifications perspective. Journal of Strategic Marketing, 24(3/4), 261-277.
Duffett, M. (2013). Understanding fandom. Bloomsbury.

Fast, K., Karlsson, M., \& Örnebring, H. (2016). Metaphors of free labor: A typology of unpaid work in the media sector. Media, Culture \& Society, 38(7), 963-978.

Fiske, J. (1992). The cultural economy of fandom. In L. A. Lewis (Ed.), The adoring audience: Fan culture and popular media (pp. 30-49). Routledge.

Franzke, A. S., Bechmann, A., Zimmer, M., \& Ess, C. M. (2020). Internet research: Ethical guidelines 3.0. Association of Internet Researchers. https://aoir.org/ reports/ethics3.pdf

Galuszka, P. (2015). New economy of fandom. Popular Music and Society, 38(1), 25-43.

Gamble, J., \& Gilmore, A. (2013). A new era of consumer marketing? European Journal of Marketing, 47(11/12), 1859-1888.

Gray, J., Sandvoss, C., \& Harrington, C. L. (Eds). (2017). Fandom: Identities and communities in a mediated world. NYU Press.

Hao, A. (2020). Understanding consumer fandom: Literature review and conceptual framework. In C. L. Wang (Ed.), Handbook of research on the impact of fandom in society and consumerism (pp. 18-37). IGI Global.

Hills, M. (2002). Fan cultures. Routledge.

Hine, C. (2015). Ethnography for the Internet: Embedded, embodied and everyday. Bloomsbury Academic.

Holt, D. B. (2004). How brands become icons: The principles of cultural branding. Harvard Business Press.

Hoxter, J. (2000). Taking possession: Cult learning in The Exorcist. In X. Mendik \& G. Harper (Eds.), Unruly pleasures: The cult film and its critics (pp. 171-186). Fab Press.

Ind, N., Iglesias, O., \& Schultz, M. (2013). Building brands together: Emergence and outcomes of co-creation. California Management Review, 55(3), 5-26.

Jenkins, H. (1992). Textual poachers: Television fans and participatory culture. Routledge.

Jenkins, H. (2006). Fans, bloggers and gamers: Exploring participatory culture. New York University Press.

Jenkins, H., Ford, S., \& Green, J. (2013). Spreadable media: Creating value and meaning in a networked culture. New York University Press.

Kermode, M. (1997). I was a teenage horror fan. In M. Barker \& J. Petley (Eds.), III effects: The media/ violence debate. Routledge.

Liang, Y., \& Shen, W. (2016). Fan economy in the Chinese media and entertainment industry: How feedback from super fans can propel creative industries' revenue. Global Media and China, 1(4), 331-349.

Lincoln, Y. S., \& Guba, E. G. (1985). Naturalistic inquiry. Sage.

MacDonald, A. (1998). Uncertain utopia: Science fiction media fandom and computer-mediated communication. In C. Harris \& A. Alexander (Eds.), Theorizing fandom: Fans, subculture, and identity (pp. 131-152). Hampton Press.

Malthouse, E. C., Haenlein, M., Skiera, B., Wege, E., \& Zhang, M. (2013). Managing customer relation- 
ships in the social media era: Introducing the social CRM house. Journal of Interactive Marketing, 27(4), 270-280.

Marcus, G. E. (1995). Ethnography in/of the world system: The emergence of multi-sited ethnography. Annual Review of Anthropology, 24(1), 95-117.

Markham, A. (2017). Ethnography in the digital Internet era. In N. Denzin \& Y. Lincoln (Eds.), Sage handbook of qualitative research (5th ed., pp. 650-668). Sage.

Markham, A., \& Buchanan, E. (2012). Ethical decision making and Internet research ethics: Recommendations from the AolR Ethics Working Committee. Association of Internet Researchers. https://aoir.org/ reports/ethics2.pdf

Midem. (2013, January 27). D2F from A to Z: Distribution: Ariel Hyatt, Cyber PR-Midem 2013 [Video]. https:// www.youtube.com/watch? $v=q Y 4 N e W x p T B 8$

Milne, G. R., \& McDonald, M. A. (1999). Sport marketing: Managing the exchange process. Jones \& Bartlett.

Morris, J. W. (2014). Artists as entrepreneurs, fans as workers. Popular Music \& Society, 37(3), 273-290.

Muntinga, D. G., Moorman, M., \& Smit, E. G. (2011). Introducing COBRAs. International Journal of Advertising, 30(1), 13-46.

O’Reilly, K. (2012). Ethnographic methods: The practice of ethnography (2nd ed.). Routledge.

Pink, S. (2016). Experience: Digital ethnography. In S. Kubitschko \& A. Kaun (Eds.), Innovative methods in media and communication research (pp. 161-165). Palgrave Macmillan.

Pongsakornrungsilp, S., \& Schroeder, J. E. (2011). Understanding value co-creation in a co-consuming brand community. Marketing Theory, 11(3), 303-324.

Postill, J., \& Pink, S. (2012). Social media ethnography: The digital researcher in a messy web. Media International Australia, 145(1), 123-134.

Sandvoss, C. (2005). Fans: The mirror of consumption. Polity Press.

Schrøder, K. C. (2019). Audience reception research in a post-broadcasting digital age. Television \& New Media, 20(2), 155-169.
Schroeder, R. (2014). Big data and the brave new world of social media research. Big Data \& Society, 1(2), 1-11.

Strauss, A. L., \& Corbin, J. M. (1990). Basics of qualitative research: Grounded theory procedures and techniques. Sage.

Terranova, T. (2000). Free labor: Producing culture for the digital economy. Social Text, 18(2), 33-58.

Tulloch, J., \& Jenkins, H. (1995). We're only a speck in the ocean: The fans as powerless elites. In J. Tulloch \& $\mathrm{H}$. Jenkins (Eds.), Science fiction audiences: Watching Doctor Who and Star Trek (pp. 144-174). Routledge.

Van den Bulck, H., Claessens, N., Mast, J., \& Kuppens, A. (2016). Representation of fandom in mainstream media: Analysis of production and content of Flemish television's superfans. European Journal of Cultural Studies, 19(6), 513-528.

Vargo, S. L., \& Lusch, R. F. (2004). Evolving to a new dominant logic for marketing. Journal of Marketing, 68(1), 1-17.

Vargo, S. L., \& Lusch, R. F. (2016). Institutions and axioms: An extension and update of service-dominant logic. Journal of the Academy of Marketing Science, 44(1), 5-23.

Wallendorf, M., \& Belk, R. W. (1989). Assessing trustworthiness in naturalistic consumer research. In E. C. Hirschman (Ed.), Interpretative consumer research (pp. 69-84). Association for Consumer Research.

Wikström, P. (2009). The music industry. Polity Press.

Williams, R. (2004). It's about power: Spoilers and fan hierarchy in on-line Buffy fandom. Slayage: The Online International Journal of Buffy Studies, 11, 1-15.

$\mathrm{Wu}, \mathrm{M}$. (2012). The science of social: Beyond hype, likes \& followers. Lithium Technologies.

Yin, R. K. (2013). Validity and generalization in future case study evaluations. Evaluation, 19(3), 321-332.

Ytre-Arne, B., \& Das, R. (2019). An agenda in the interest of audiences: Facing the challenges of intrusive media technologies. Television \& New Media, 20(2), 184-198.

Zeiser, A. (2015). Transmedia marketing: From film and TV to games and digital media. Focal Press.

\section{About the Authors}
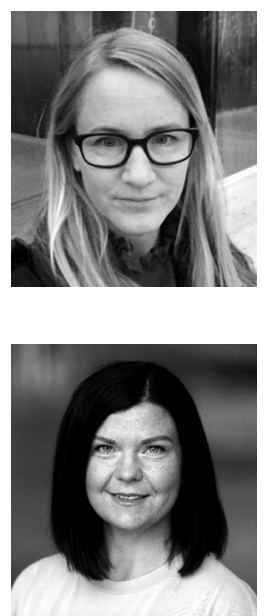

Jessica Edlom is a Doctoral Student in Media and Communication and Adjunct Teacher at Karlstad University, Sweden. She is part of the EU-funded Interreg Sweden-Norway research project MECOMusic Ecosystems Inner Scandinavia. Her research is focused on strategic communication, communication management, and brand building. Jessica's research has appeared in several books and journals, including Popular Music, Technology and the Changing Media Ecosystem, and the International Journal of Music Business Research. Prior to her career in academia, Jessica worked in advertising and strategic communication for both private and public organizations.

Jenny Karlsson is an Assistant Professor in Business Administration based at CTF, Service Research Centre, at Karlstad Business School, Karlstad University. Jenny is currently the Project Leader of the EU-funded Interreg Sweden-Norway research project MECO-Music Ecosystems Inner Scandinavia, in which she is conducting empirical research on the music industry. Her research interests focus on service innovation and service management. Jenny's work has appeared in several books and journals, including the European Journal of Marketing and the Service Industries Journal. 